\title{
INORGANICARD: UM JOGO DE CARTAS COMO ESTRATÉGIA DE APRENDIZAGEM ATIVA PARA O ENSINO DE ELETRONEGATIVIDADE
}

\author{
Taís Arthur Corrêa \\ Giuslane Ferreira Machado \\ Nilza da Silva Morais \\ Tatiana da Costa Coelho
}

\section{Introdução}

Ao longo dos anos têm-se observado as transformações do ensino, principalmente no processo de aprendizagem, no desafio de torná-lo mais prazeroso e atrativo sob o ponto de vista do discente. Vivemos uma mudança no perfil de nosso alunado, onde um dos grandes desafios está no engajamento dos estudantes nas atividades escolares, exigindo dinamismo e interatividade e, com isso, emergem novas provocações para a educação contemporânea.

Para os estudantes do século XXI, devido ao avanço das tecnologias, o ensino tradicional baseado no modelo passivo/expositivo já não é capaz de atender totalmente as demandas, contribuindo para situações de apatia, desconforto e desinteresse por parte do aluno, 
sendo ainda, um dos paradigmas educacionais a serem solucionados nas salas de aula do Brasil (SILVA; SALES; CASTRO, 2019).

Neste cenário, têm-se acompanhado os esforços de pesquisadores e professores para o desenvolvimento e aplicação de novas metodologias que visem despertar o interesse dos alunos para aprendizagem, principalmente na educação básica, enxergando-a de forma menos complexa e mais atrativa (OLIVEIRA; SILVA; FERREIRA, 2010; NICOLA; PANIZ, 2016; SEIXAS, CALIBRÓ, SOUZA, 2017; CORREA et al., 2020). Dentre elas, o uso de metodologias ativas no ensino apresenta-se como uma proposta inovadora na busca pelo aprendizado, além de despertar o interesse e a motivação dos estudantes, especialmente em disciplinas da área de ciências.

As metodologias ativas compreendem técnicas de ensino que colocam o aluno no cerne do processo pedagógico, dando ênfase à aprendizagem por descoberta e investigação, experimentando, criando e se envolvendo ativamente, concedendo-lhe assim o papel de protagonista na construção de sua própria aprendizagem, contrapondo-se, desse modo, à abordagem da educação tradicional, possibilitando uma aprendizagem significativa o que possibilita a construção do sujeito autônomo (MORÁN, 2015; BACICH; TANZI NETO; TREVISANI, 2015). 
Ainda no contexto de renovação e implantação de metodologias de ensino diferenciadas, a ludicidade também é uma interessante ferramenta de trabalho, propiciando uma participação mais ativa do aluno na construção do conhecimento. Lúdico é o adjetivo dado a tudo aquilo que possua a natureza de brincar, promover divertimento, recreação e alegria, capaz de envolver o indivíduo de forma motivacional. Dentre os objetos de ludicidade, os jogos didáticos vêm ganhando destaque ao formar um elo entre a diversão e o ensino, contribuindo para o desenvolvimento do raciocínio cognitivo, levando a construção de competências e habilidades nos estudantes (KISHIMOTO, 2011; ZANON; GUERREIRO; OLIVEIRA, 2008; SOARES; RESENDE, 2019).

Os jogos usados nas práticas pedagógicas se tornam ferramentas valorosas no processo de ensinoaprendizagem ao proporcionar interação e diversão aos discentes, uma vez que lança desafios a serem vencidos através dos objetivos propostos, despertando interesse do aluno, tornando um conteúdo que antes era abstrato mais prático e próximo da realidade do discente. De acordo com os Parâmetros Curriculares Nacionais (PCN) os jogos seriam uma forma lúdica e prazerosa ao se relacionar com o conteúdo escolar (BRASIL, 2006). Além disso, têm-se mostrado como uma alternativa envolvente, engajadora e motivadora dos estudantes em relação à química, em ambientes de aprendizagem (CUNHA, 2012; 
FOCETOLA, 2012; MATIAS; NASCIMENTO; SALES, 2017).

A química é uma ciência abstrata e seu conhecimento marcado por uma linguagem científica e própria, formado por símbolos, equações, fórmulas, etc. Considerada de difícil compreensão entre os estudantes, não somente pela linguagem, mas pela forma de como é apresentada, dando ênfase na memorização dos conteúdos, sem uma associação com o cotidiano dos discentes (BORGES, 2011; SILVA, 2013).

Quando nos referimos ao ensino da Tabela Periódica e suas propriedades, especificamente, na maioria dos casos é observado que a abordagem do conteúdo ocorre de forma tradicional, onde o professor é o detentor do saber e o aluno mero receptor de informações. Visando tornar o ensino desses conceitos mais acessíveis e contextualizados, diferentes trabalhos propõem metodologias inovadoras de aprendizagem. Dallacosta, Fernandes e Bastos (1998) desenvolveram um software com o propósito de facilitar o processo de ensino-aprendizagem propondo a integração de textos e animações, favorecendo a interatividade e o desenvolvimento auto didático; Teixeira et al (2012) avaliaram uma proposta didática abrangendo a história da construção da Tabela Periódica, permitindo a reflexão em torno da natureza da ciência e o trabalho do cientista e Romano et al. (2017) desenvolveram um jogo de tabuleiro para ampliar a compreensão de 
características particulares dos elementos químicos, abordando sua parte histórica e a menção da contribuição feminina no desenvolvimento da Química.

Partindo dessa ideia, considera-se a utilização de jogos didáticos como um instrumento amplamente usado em metodologias alternativas no processo ensinoaprendizagem, uma vez que o aluno estará envolvido de forma participativa na construção do conhecimento, podendo proporcionar um ambiente agradável e lúdico para o aprendizado, e mediar a interação do aluno com a ciência (SOARES, 2008).

Dessa forma, o objetivo deste trabalho foi a elaboração, validação e avaliação de um jogo didático, usado como ferramenta ativa para abordagem da propriedade periódica eletronegatividade, aplicada a alunos do ensino médio, de modo a promover uma revisão do conteúdo que intensifique o engajamento dos discentes, despertando, através do lúdico, o interesse discente pela Química e uma aprendizagem significativa.

\section{Metodologia}

O trabalho refere-se a um estudo de caso de natureza qualitativa dentro da perspectiva da pesquisa-ação como método intervencionista da prática pedagógica, utilizando-se como instrumentos de coleta de dados, anota- 
ções em campo, conversas informais e questionários, com objetivo de inferir sobre as potencialidades do jogo didático na aprendizagem de conceitos científicos. Foi realizado com 25 estudantes do $1^{\circ}$ ano do Ensino Médio regular, período diurno, com idade entre 15 e 17 anos, durante o $3^{\circ}$ bimestre de 2013, nas dependências da Escola Estadual Doutor Levindo Coelho e da Universidade do Estado de Minas Gerais (UEMG), ambos localizados no município de Ubá, Minas Gerais.

O estudo foi estruturado em três etapas: (i) elaboração do jogo didático Inorganicard, por meio da escolha da temática, construção das cartas, definição das regras e impressão do material; (ii) oficina de aplicação do jogo com registro em diário de campo; (iii) aplicação de questionários, antes e após a utilização do jogo, respondido individualmente.

A temática para a construção do jogo foi definida mediante a avaliação dos Conteúdos Básicos Comuns (CBC) de Minas Gerais, que apresentam uma proposta curricular de Química para o Ensino Médio, contemplando os conteúdos ditos essenciais na primeira série, dando enfoque ao Eixo Temático II - Modelos, Tema 2: Constituição e organização dos materiais.

Utilizou-se o formato de um jogo de cartas trabalhando informações como, por exemplo, conceitos, termos, classificações e símbolos, impressos em cartões. Pa- 
ra construção das regras, empregou-se como base o jogo "Bisca" (ou Bríscola), que se utiliza do baralho espanhol cujo objetivo é o acúmulo de pontos, baseando-se nas cartas que são retiradas e descartadas. De forma bem simplificada, nesse jogo as cartas (reis, valetes, damas, etc.) apresentam pontuações diferentes e o naipe escolhido (espadas, paus, copas ou ouros), também chamado de "trunfo", predomina sobre os demais quando as cartas descartadas forem recolhidas, tendo assim a maior pontuação. O jogo inicia quando os participantes descartam uma carta, das 3 (três) que receberam no início da brincadeira. O ganhador da rodada será aquele que jogar a carta de maior valor, observando as que foram descartadas naquela jogada, levando todas as cartas sobre a mesa. Ao final do jogo, realiza-se a soma dos pontos das cartas obtidas após a partida, sendo o vencedor o jogador que acumular 60 ou mais pontos (BISCA, 2020).

O jogo elaborado possui formato de um baralho tradicional, estampado em um lado (Face) informações dos elementos químicos, os naipes (substituindo os tradicionais por outros) ou cartas curinga, e em outro lado um padrão comum a todas as cartas deste baralho, com o nome do jogo Inorganicard. Para elaboração do conteúdo e design das cartas do jogo foram utilizados, respectivamente, os livros didáticos de Química para o Ensino Médio: Química na Abordagem do Cotidiano (PERUZZO; CANTO, 2006) e Química Geral (USBERCO; SALVADOR, 2006); e os aplicativos: Microsoft Office 
Word 2007, PDF (Portable Document Format) e CorelDraw Graphics Suite 2010. As cartas foram inicialmente construídas em papel cartão e após sua conclusão, impressas em gráfica em material semelhante ao do baralho comercial.

A atividade foi realizada no horário regular das aulas, com explicação prévia do conteúdo Tabela Periódica e suas propriedades, por meio de aula expositiva pela professora regente, visando a reforçar os conceitos abordados. Em seguida, a atividade foi apresentada aos alunos, esclarecendo seus objetivos e regras, solicitando aos participantes que estudassem o conteúdo ministrado. $\mathrm{O}$ jogo foi realizado na aula seguinte da disciplina de química, com o acompanhamento da professora. A turma foi dividida em grupos de até 6 participantes, que jogaram individualmente. $\mathrm{O}$ diário de campo foi estruturado de forma a registrar os dados, informações e resultados sobre cada etapa, contemplando os itens: data; objetivo; orientações e observações.

Com objetivo de avaliar a dimensão educativa no processo ensino-aprendizagem foi aplicado um mesmo questionário, com perguntas abertas (Quadro 1), aos alunos em duas etapas: na primeira o questionário, identificado como pré-teste, aplicado antes da aplicação do jogo e o outro questionário o pós-teste, logo após término da atividade, sendo que neste último foram acrescentadas questões fechadas sobre o jogo e a respeito do interesse 
dos alunos pela atividade desenvolvida. Posteriormente os dados foram tabulados e analisados.

Quadro 1. Perguntas dos questionários pré-teste e pós-teste aplicados aos estudantes.

Questões do Pré-teste e pós-teste:

Questão 1: 0 que você entende por eletronegatividade?

Questão 2: Qual o elemento mais eletronegativo e o menos eletronegativo da Tabela Periódica.

Questão 3: Na familia dos halogênios, qual elemento é o menos eletronegativo?

Questão 4: Através de esquema de setas, represente como a eletronegatividade cresce nos períodos e nas familias.

Questão 5: Qual a relação entre eletronegatividade e raio atômico?

Questões adicionados a0 Questionário pós-teste:

Questão 6: 0 jogo Inoganicard ajudou na compreensão do conteúdo?

( ) $\operatorname{Sim}($ ) Um pouco ( ) Não

Questão 7: 0 que você achou do jogo Inorganicard?

( ) Muito legal

( ) Não gostei

( ) Gostei, mas tive dificuldade. Qual?

Questão 8: 0 uso do jogo nas aulas de Química aumentou seu interesse em estudar a disciplina?

( ) $\operatorname{Sim}$ ( ) Não

Fonte: elaborado pelos autores.

A aplicação da proposta foi realizada com consentimento da direção e coordenação escolar, por meio de assinatura de termo de autorização, além da supervisão e 
participação da professora regente, utilizando a sala de aula como ambiente de pesquisa.

\section{Elaboração do jogo didático}

O jogo Inorganicard foi elaborado como objeto de trabalho de Conclusão de Curso de Licenciatura em Química, em colaboração com o Curso de Design, ambos da UEMG, unidade Ubá. A temática do jogo foi selecionada com base na proposta curricular para o Currículo Básico Comum (CBC) de Química, organizado em eixos temáticos, desdobrados em tópicos/habilidades e detalhamento de habilidades, tendo em vista a revisão do conteúdo previamente trabalhada pela disciplina na primeira série do ensino médio (MORTIMER, MACHADO, ROMANELLI, 2000; MINAS GERAIS, 2007).

Um exemplo da articulação dos pontos propostos pelo CBC é reconhecer os elementos químicos e organizálos na Tabela Periódica, dando destaque às suas propriedades, dentre elas a eletronegatividade. Este assunto encontra-se situado no Eixo Temático II - Modelos, Tema 2: Constituição e organização dos materiais, Tópico 6: Representação para os átomos; subtópico 6.4: Usar a Tabela Periódica para reconhecer os elementos, seus símbolos e as características de substâncias elementares (MINAS GERAIS, 2005; MINAS GERAIS, 2018). 
O jogo possui formato de um baralho, no tamanho de $8,9 \mathrm{~cm} \times 5,7 \mathrm{~cm}$, estampado em um lado (Face), diferentes informações sobre os elementos químicos (nome, símbolo, família e período) e cartas curinga, e em outro lado um padrão comum a todas as cartas, o nome do jogo Inorganicard (Figura 1).

Figura 1. Ilustração das cartas do baralho Inorganicard (face e verso).

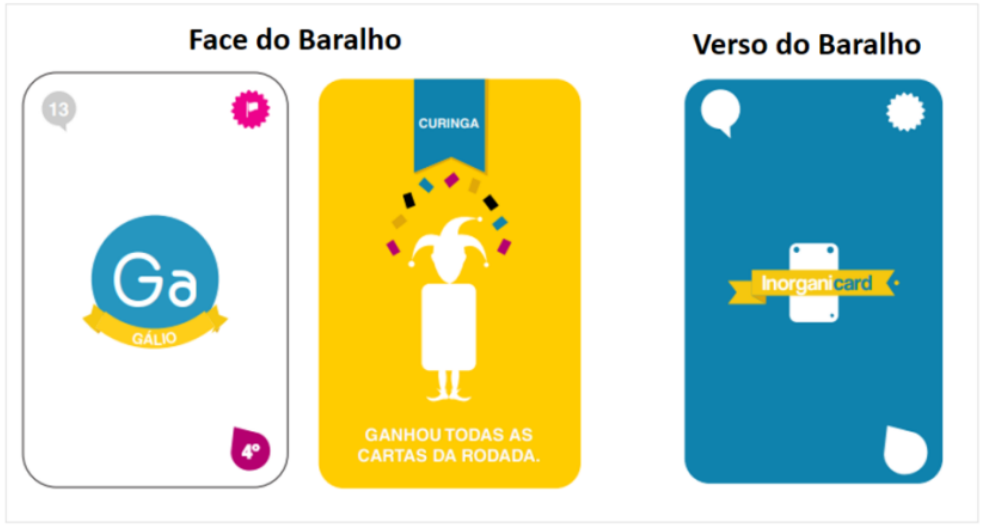

Fonte: elaborado pelos autores.

De acordo com a Figura 2, na face das cartas se encontram as informações sobre os elementos químicos, dispostos da seguinte forma: no centro a representação química acompanhada do seu respectivo nome; no canto superior esquerdo a indicação da família a qual pertence e no canto inferior direito o dado referente ao período ocupado na Tabela Periódica. Ainda na face, no canto superior direito, encontram-se os naipes, que foram substi- 
tuídos do baralho tradicional por representações lúdicas, como: bomba, lâmpada, copo e bandeirinha, com pontuações específicas variando de acordo com a eletronegatividade dos elementos químicos (mais eletronegativos apresentam maior pontuação) para que, ao fim do jogo, possam ser somados e assim determinar o vencedor daquela partida. Os valores dos naipes bem como suas descrições/significados estão representados na Tabela 1. As cartas curingas apresentam as informações: "Fique duas rodadas sem jogar", "Passe a vez", "Ganhou todas as cartas da rodada" e "Troque uma de suas cartas por uma do montinho".

Figura 2. Distribuição das informações na face das cartas do baralho do Jogo Inorganicard.

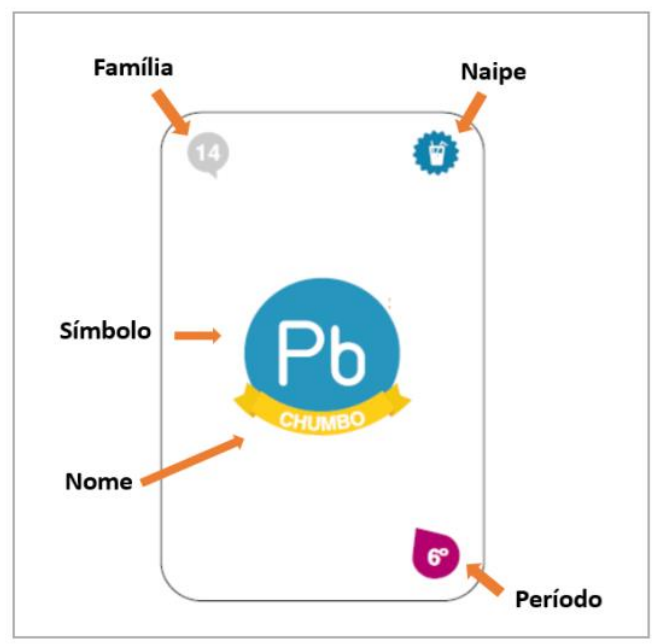

Fonte: elaborado pelos autores. 
Tabela 1. Naipes das cartas do Jogo Inorganicard com suas respectivas descrições e valores.

\begin{tabular}{clc}
\hline Naipe & \multicolumn{1}{c}{ Descrição } & Valor \\
\hline & \multicolumn{1}{c}{ Bomba: você está mal } & 1 \\
\hline & $\begin{array}{l}\text { Lâmpada: Começou a melhorar. } \\
\text { Existe uma luz no seu caminho... }\end{array}$ & 2 \\
\hline & $\begin{array}{l}\text { Copo: Bem melhor, merece um } \\
\text { refresco, ou seja, são mais pontos }\end{array}$ & 3 \\
\hline
\end{tabular}

Fonte: elaborado pelos autores.

Com o intuito de torná-lo adequado para aplicação em uma aula de 50 minutos, fazem parte deste jogo de baralho, apenas os elementos químicos representativos não sintéticos das famílias: 1 (metais alcalinos), 2 (metais alcalinos terrosos), 13 (família do boro), 14 (família do carbono), 15 (família do nitrogênio), 16 (calcogênios) e 17 (halogênios) da Tabela Periódica. Deste modo o jogo final é composto por 48 cartas de baralho divididas em: 37 cartas com as informações referentes aos elementos químicos/naipes e 11 cartas curinga.

As cores selecionadas para sua elaboração foram pensadas na inclusão de pessoas com daltonismo, descartando-se assim as cores vermelha e verde. Ainda nessa premissa, foram impressas cartas em tamanhos maiores 
(14,0 cm x 8,9 cm), objetivando a inserção de alunos com baixa visão. Para Carmo (2015), os jogos pedagógicos podem ser um rico material para a educação inclusiva, pois desenvolve a criatividade, a imaginação e a concentração de maneira eficaz. Para isso, os professores devem buscar metodologias adequadas para promover a integração dos discentes com deficiência. Ainda nessa perspectiva, Goya e Basso (2014) complementam que os materiais didáticos devem levar em consideração os discentes com deficiência de modo que possam interagir e com isso promover a inclusão.

A brincadeira pode ser composta por no mínimo 2 (dois) e no máximo 6 (seis) participantes. No início, cada jogador recebe 3 (três) cartas, sendo as demais dispostas no centro da mesa, na forma de monte, com as faces viradas para baixo. Com o auxílio de um dado é determinado qual jogador inicia a partida, sendo aquele que tirou o maior número. $\mathrm{O}$ jogo começa e o primeiro jogador escolhe e descarta uma das cartas recebidas sobre a mesa, e os outros vão jogando cada um na sua vez, seguindo a brincadeira no sentido horário.

Os jogadores devem observar nas cartas descartadas a qual família e período da Tabela Periódica os elementos químicos pertencem, além do valor do naipe atribuído (Tabela 1), pois recolhe as cartas daquela rodada o que apresenta o elemento de maior eletronegatividade, iniciando também a próxima jogada. Durante todo o jogo 
os alunos utilizam como apoio/consulta a Tabela Periódica, o que facilita a identificação e localização dos elementos químicos, além do crescimento do valor da eletronegatividade.

Em seguida é solicitado aos participantes a retirarem uma nova carta do monte (começando por aquele que ganhou a rodada), já que cada jogador tem 2 (duas) cartas nas mãos, voltando ao número de 3 (três) cartas para cada. Essas ações se repetem até acabarem todas as cartas do baralho e, por final, não restarem também nenhuma nas mãos de todos os jogadores. Vale ressaltar que, quando o jogador retira uma carta curinga cuja ação é não participar dessa ou das próximas duas rodadas, ele não retira uma nova carta do baralho (monte), ficando com o número de 2 (duas) cartas até o momento que volta para a partida. $\mathrm{O}$ vencedor será o jogador que acumulou o maior número de pontos ao final do jogo, somandose as cartas (naipes) que ele recolheu em cada rodada vitoriosa. No caso de empate ganha aquele que possui a carta do elemento com maior eletronegatividade.

\section{Aplicação do jogo e avaliação da metodologia}

De acordo com as respostas do questionário préteste (Figura 3), foi observado que mesmo com a explicação prévia do conteúdo Tabela Periódica e suas propriedades, os alunos não estavam familiarizados com a temá- 
tica abordada e alguns conceitos não tinham sido compreendidos. Observou-se que as repostas das questões $1 \mathrm{a}$ 5, apresentaram um percentual elevado de erros, variando de $59 \%$ a $91 \%$, estando entre os maiores percentuais de respostas incorretas as questões que exigiam definição de conceitos, como eletronegatividade e sua associação com as famílias/períodos da Tabela Periódica.

$\mathrm{Na}$ aula que antecedeu a aplicação da atividade, o jogo foi apresentado e as regras explicadas de forma detalhada aos estudantes. Esta ação otimizou sua aplicação, pois os alunos passaram a conhecer previamente o jogo, suas características e objetivos, otimizando o tempo para a realização da brincadeira na aula seguinte.

Figura 3. Quantitativo das respostas corretas e erradas referentes às questões 1 a 5 dispostas no pré-teste.

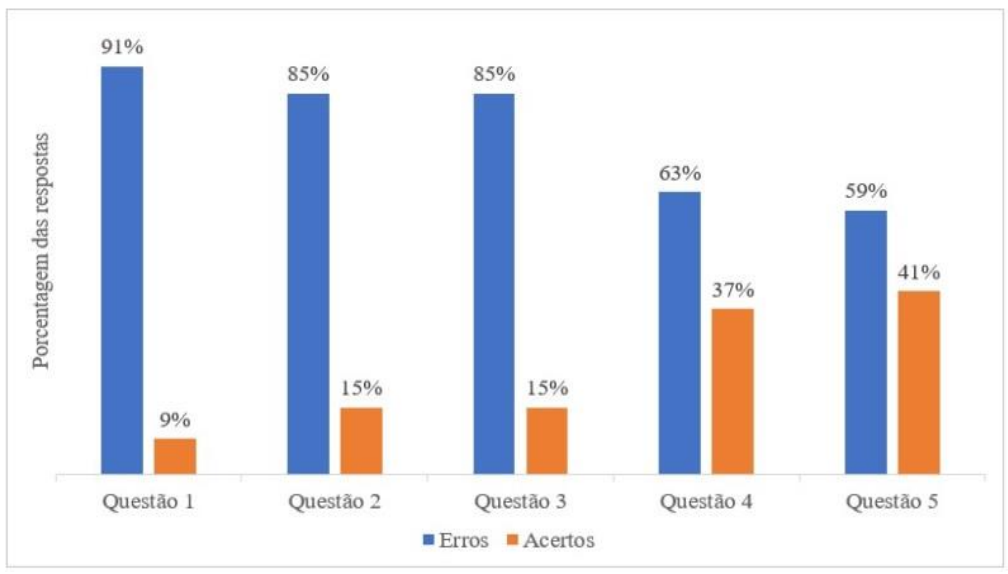

Fonte: elaborado pelos autores. 
$\mathrm{Na}$ aula que antecedeu a aplicação da atividade, o jogo foi apresentado e as regras explicadas de forma detalhada aos estudantes. Esta ação otimizou sua aplicação, pois os alunos passaram a conhecer previamente o jogo, suas características e objetivos, otimizando o tempo para a realização da brincadeira na aula seguinte.

A atividade teve duração de 40 minutos, o que facilitou sua realização em uma aula (50 minutos). O espaço da sala de aula foi adequado para a promoção da atividade, em que os grupos de estudantes ficaram bem distribuídos, e o barulho gerado devido à interação entre eles ficou restrita ao espaço determinado, não atrapalhando as aulas das salas vizinhas.

De acordo com Santanna (2015), o planejamento das atividades pedagógicas tem características próprias e deve levar em consideração o tempo, organização da atividade e uma reflexão sobre a forma com que será aplicada aos alunos. Com isso, o professor reflete e sistematiza sua ação, tornando sua prática eficiente.

Durante a aplicação do jogo os alunos se mostraram animados com a dinâmica, interagindo, trocando informações, em um ambiente descontraído e prazeroso de aprendizagem. Segundo Cunha (2012) os jogos didáticos são capazes de desenvolver no estudante diversas habilidades, tanto campo do conhecimento como no afetivo e social, através de diferentes fatores: aprendizagem de 
conceitos de forma mais rápida, desenvolvimento da cognição, favorecimento da socialização, desenvolvimento da sensibilidade e o estreitamento de laços de amizade e afetividade.

Através dos seus estudos, Henri Wallon (2014) demonstra que a dimensão afetiva do ser humano é bem significativa para a construção do conhecimento, sendo a afetividade e inteligência inseparáveis e a sala de aula é o espaço para a construção dessa afetividade principalmente no período da adolescência que é marcada normalmente por alterações físicas e emocionais e exige uma gerência das relações racionais e afetivas.

Observou-se também um estreitamento na relação professor-aluno, diante da participação da docente na brincadeira, auxiliando alguns estudantes com as dúvidas durante sua aplicação, dentre elas a interpretação da Tabela Periódica. Para Vygotsky (2013), a interação entre aluno e professor se faz necessária através da mediação, que se torna o ponto central do processo educativo. Desse modo, nesse momento, o docente se transforma no mediador do conhecimento e o aluno sujeito na construção e transformação do saber. Vygotsky é considerado um dos pioneiros na inserção das atividades lúdicas na educação, destacando a importância do ato de brincar para o desenvolvimento intelectual. 
Diante das respostas das questões 1 a 5 do pósteste (Figura 4), observou-se que houve uma diminuição significativa no número de repostas incorretas, variando de 8 a 27\%. Em entrevista informal após a aplicação do questionário, os estudantes relataram que as questões estavam mais fáceis de responder, pois conseguiram lembrar do conteúdo por associação com o jogo e reforçaram o aprendizado sobre o uso da Tabela Periódica. De acordo com Soares e Resende (2019), tal fato fortalece a designação do jogo Inorganicard como didático, no qual a atividade é utilizada como forma de reforço do conteúdo previamente ministrado, diferenciando-o de um jogo educativo no qual as atividades desenvolvidas são implementadas como ferramenta de ensino.

Figura 4. Quantitativo das respostas referente às questões 1 a 5 do pós-teste

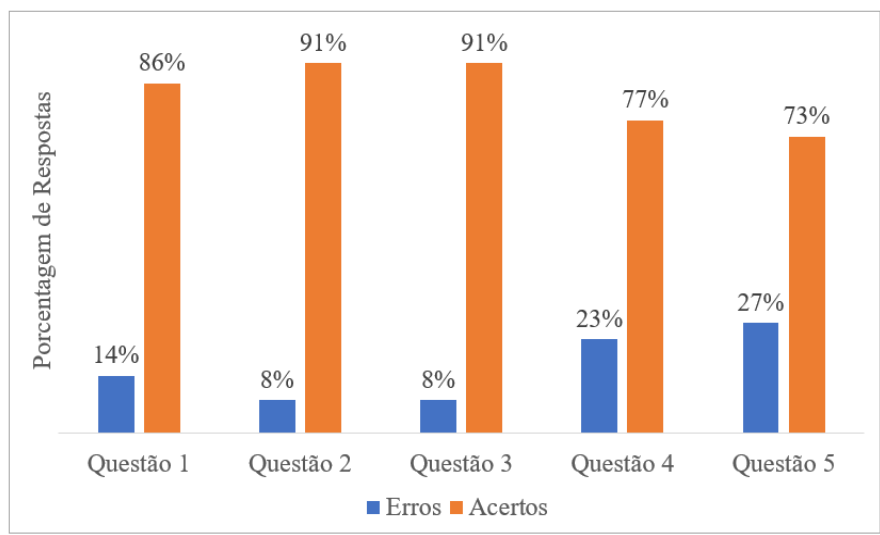

Fonte: elaborado pelos autores. 
Acredita-se que, ao se trabalhar diferentes informações na atividade proposta, como, por exemplo, os nomes e símbolos dos elementos químicos, a localização na Tabela Periódica e classificação por período e família, o jogo proporcionou um resumo do conteúdo, articulando subtópicos relevantes referente ao assunto contemplado, além da possibilitar ao aluno uma forma diferenciada de se familiarizar com a linguagem química.

Segundo Morán (2015), as metodologias de ensino empregadas devem concordar com o resultado que se espera obter, no caso do jogo em questão, utilizam-se as metodologias ativas ao despertar no aluno a participação proativa no processo aprendizagem permitindo que o aluno busque o conhecimento, alinhando teoria com a prática, de modo a torná-los críticos-reflexivos. Ainda no contexto das metodologias ativas, pode-se destacar que os jogos didáticos atuam como modo alternativo e mediador da aprendizagem, auxiliando também no desenvolvimento de habilidades como observação, organização, reflexão e argumentação dos temas referentes aos conteúdos abordados.

Fazendo um comparativo entre o número de acertos no questionário pré-teste e no pós-teste, observou-se que houve um aumento animador no número de respostas corretas, variando de $8 \%$ a $41 \%$ no pré-teste e de 73 a $91 \%$ no pós-teste, como pode ser observado na Figura 5 . 
Figura 5. Comparação do quantitativo de respostas corretas das questões 1 a 5 obtidas após aplicação do pré-teste pós-teste.

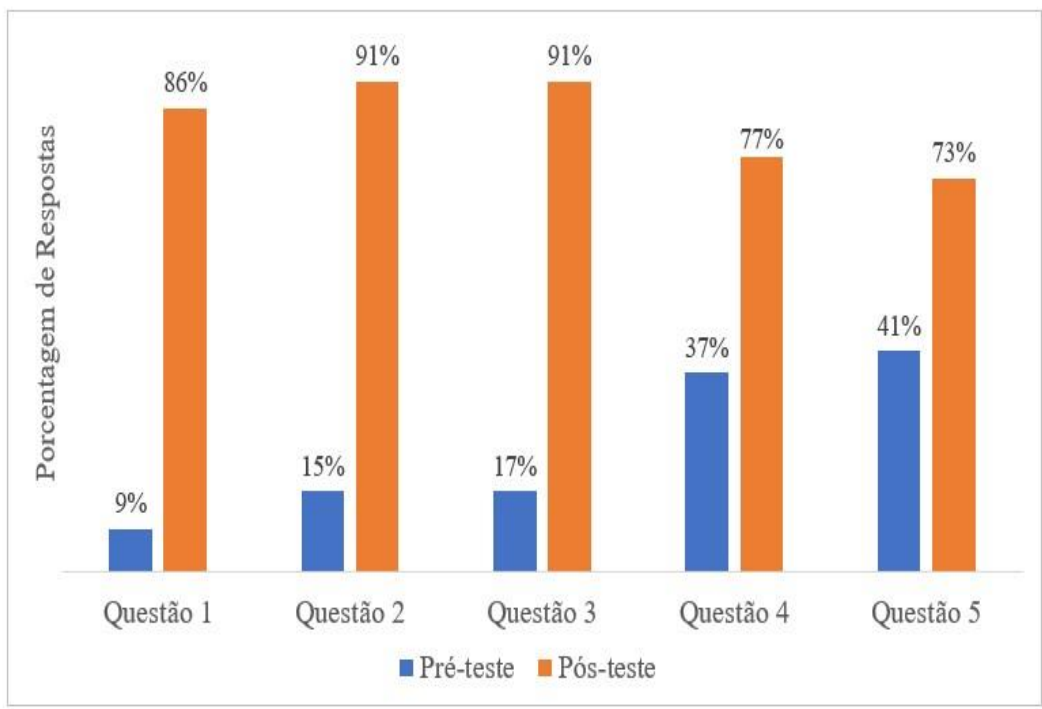

Fonte: elaborado pelos autores.

Tal fato é corroborado através da resposta da questão 6, na qual 86\% julgaram que a atividade proposta auxiliou na compreensão do conteúdo abordado e 14\% responderam que a atividade não contribuiu na compreensão do mesmo.

Através do exposto, observou-se que o jogo didático despertou o interesse dos alunos pela disciplina e criou um ambiente propício para a aprendizagem. De acordo com Pereira, Fusinato e Neves (2009) os jogos educacionais, transformaram-se em ferramentas de ensi- 
no para estudantes que possuem dificuldades de aprendizagem, pois através dos jogos os alunos, gradativamente vão modificando a imagem negativa do ato de conhecer, tendo uma experiência em que aprender é uma atividade interessante e desafiadora.

Em entrevista informal com a professora regente, a mesma relatou que a atividade teve boa aceitação pelos estudantes, apresentando-se eficaz como instrumento facilitador do processo ensino-aprendizagem, auxiliando como ferramenta prática de aplicação do conteúdo e, portanto, contribuindo para sua fixação. Esse fato foi corroborado pelas notas dos estudantes na avaliação bimestral, em comparação com outras turmas que não participaram da atividade.

Seguindo o próximo quesito avaliado, corresponde à impressão dos alunos sobre o jogo (questão 7), 11\% não gostaram do jogo, 60\% consideraram o jogo muito legal e $29 \%$ responderam que tinham gostado, mas sentiram dificuldade em compreender alguma parte da atividade (Figura 6), dando como exemplo as regras do jogo. Tal fato pode ser justificado pelo fato do jogo Bisca não ser uma brincadeira amplamente conhecida por todos os estudantes da turma, o que pode ter contribuído para seu não completo entendimento. 
Figura 6. Quantitativo das respostas referente à questão 7 do pósteste.

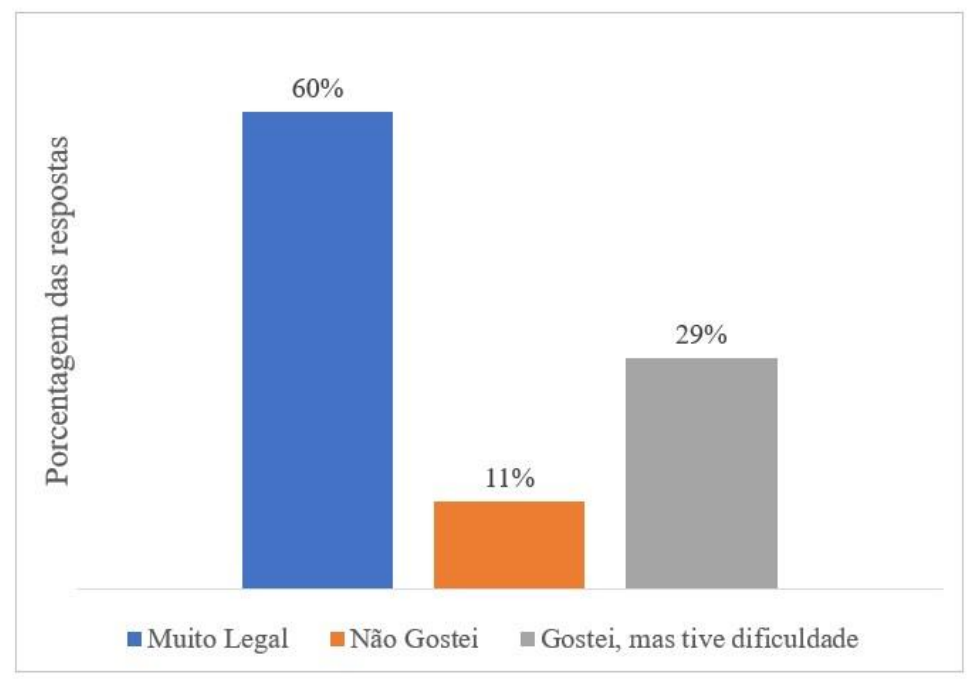

Fonte: elaborado pelos autores.

Soares (2008) apresenta em seu trabalho que para o desenvolvimento de um jogo didático e obtenção de bons resultados em sua aplicação é necessário, dentre outras características, a presença de regras e objetivos bem esclarecidos. De acordo com o autor, as regras do jogo podem levar o sucesso dos jogos didáticos ou atividades lúdicas em ensino de ciências, mantendo um equilíbrio entre a função do jogo e sua proposta pedagógica.

Quando questionados sobre o estímulo ao estudo de química após a utilização do jogo didático, 79\% dos alunos afirmaram que o jogo Inorganicard aumentou o 
interesse pela disciplina. O estímulo ao estudo após a utilização de atividades lúdicas também foi observado e discutido por diversos pesquisadores como Oliveira, Silva e Ferreira (2010), Zub (2012), Leal (2016), Silva, Lacerda e Cleophas (2017), corroborando com a contribuição da metodologia no fortalecimento de diferentes aspectos necessários para a melhoria do processo de ensinoaprendizagem da química.

\section{Considerações finais}

O jogo Inorganicard, utilizado em sala de aula, apresentou-se como recurso interessante para trabalhar a temática eletronegatividade, dentro do conteúdo disciplinar Tabela Periódica, como metodologia ativa para o ensino química. A aplicação do jogo didático foi capaz de favorecer o processo de consolidação do conhecimento de forma dinâmica e prazerosa, por meio da familiarização com a linguagem química, síntese/revisão de conceitos importantes do conteúdo, o que refletiu no aumento da porcentagem de acertos das questões após a aplicação do jogo didático, e estreitamento da relação aluno-aluno e professor-aluno, através da ajuda mútua entre os discentes e apoio do educador na resolução de dúvidas no decorrer do desenvolvimento da atividade. Entretanto, ressalta-se que o jogo em si não substitui os métodos de ensino, atuando de forma complementar no processo educativo. 
Diante dos resultados obtidos, observou-se que o jogo didático desenvolvido foi um facilitador no processo de aprendizagem significativa dos estudantes, evidenciando a colaboração participativa dos discentes e intensificou o engajamento do aprendiz e o desenvolvimento de suas competências, proposta principal das metodologias ativas no processo ensino-aprendizagem, além de ser uma alternativa simples, viável e capaz de despertar o interesse dos alunos.

\section{Referências}

BACICH, L.; TANZI NETO, A.; TREVISANI, F. de M. (Orgs.) Ensino híbrido: personalização e tecnologia na educação. Porto Alegre: Penso, 2015.

BISCA. Jogo de Cartas: o mundo das cartas em suas mãos. [S.I].

Disponível

em: <http://jogosdecartas.hut.com.br/bisca/> Acesso em: 28 dez. 2020.

BORGES, A. A; SILVA, C.M. A Docência em Química: Um Estudo das Concepções dos Professores da Rede Pública de Formiga-MG. Periódicos, Vol. 6, n. 2, 2011.

CARMO, E. T. Importância dos jogos como metodologia da educação inclusiva na Escola Municipal Morro Encantado em Cavalcante Goiás. 2015. 39 f. Trabalho de Conclusão de Curso (Especialização em Desenvolvimento Humano, Educação e Inclusão Escolar) - Universidade de Brasília, Brasília, 2015. 
CORREA, T. A.; MARTINS, H. L.; MILLAN, R. N.; MARANGONI, A. C. Uma experiência didática através da ferramenta Stop Motion para o ensino de Modelos Atômicos. HOLOS, Ano 36, v. 6, p.1-12, 2020.

CUNHA, M. C. Jogos no Ensino de Química: Considerações Teóricas para sua Utilização em Sala de Aula. Química Nova na Escola, v.34, n.2, p. 92-98, maio, 2012.

DALLACOSTA, A.; FERNANDES, A. M. R.; BASTOS, R. C. Desenvolvimento de um software educacional para o ensino de química relativo à Tabela Periódica. In: IV Congresso RIBIE, Brasília, 1998. Disponível em: < http://www.c5.cl/ieinvestiga/actas/ribie98/16o.html>. Acesso em: 26 dez. 2020.

FOCETOLA, P. B. M.; et al. Os Jogos Educacionais de Cartas como Estratégia de Ensino de Química. Química Nova na Escola, v.34, n.4, p.248-25, 2012.

GOYA, P. R. L.; BASSO, S. P. S. Materiais didáticos de ciências e biologia para alunos com necessidades educacionais especiais. Revista da SBEnBio, Niterói, v. 7, n. 7, p. 6173-6184, 2014.

KISHIMOTO, T. M. Jogo, brinquedo, brincadeira e a Educação. 14. ed. São Paulo: Cortez, 2011.

LEAL, H. G.A. Uso da abordagem lúdica no Ensino de Química. Trabalho de Conclusão de Curso (Especialização em Ensino de Ciências por Investigação), Universidade Federal de Minas Gerais, Faculdade de Educação, 2016.

MATIAS, F. S.; NASCIMENTO, F. T.; SALES, L. L. M. Jogos lúdicos como ferramenta no ensino de Química: teoria versus prática. Revista de Pesquisa Interdisciplinar, Cajazeiras, n.2, suplementar, p. 452-464, set. de 2017. 
MINAS GERAIS, Governo de. Secretaria de Estado da Educação (SEE). Conteúdo Básico Comum (CBC) de QUÍ́MICA do Ensino Médio: Exames Supletivos/2018. Disponível em: <http://www2.educacao.mg.gov.br/images/Progr._Qu\%C3\%A Dmica_M\%C3\%A9dio_2018.pdf >._Acesso em: 19 ago. 2020.

. Secretaria de Estado da Educação (SEE). Química: proposta curricular. Educação Básica. Belo Horizonte: 2005.

. Secretaria de Estado da Educação (SEE). Química: proposta curricular. Educação Básica. Belo Horizonte, 2007.

MORÁN, J. Mudando a educação com metodologias ativas. Coleção Mídias Contemporâneas. Convergências Midiáticas, Educação e Cidadania: aproximações jovens, v. 2, p. 15-33, 2015 .

MORTIMER, E. F.; MACHADO, A. H.; ROMANELLI, L. I. A proposta curricular de química do estado de minas gerais: fundamentos e pressupostos. Química Nova, v. 23, n.2, p.273282, 2000 .

NICOLA, J. A.; PANIZ, C. M. A importância da utilização de diferentes recursos didáticos no ensino de biologia. InFor, v. 2, n. 1, p.355-381, 2016.

OLIVEIRA, L. M. S.; SILVA, O. G.; FERREIRA, U. V. da S. Desenvolvendo jogos didáticos para o ensino de química. HOLOS, ano 26, 2010.

PEREIRA, R. F.; FUSINATO, P. A.; NEVES, M. C. D. Desenvolvendo um jogo de tabuleiro para o ensino de Física. In: ENCONTRO NACIONAL DE PESQUISA EM EDUCAÇÃO EM CIÊNCIAS, 7., 2009, Florianópolis. Anais[...] Florianópolis: UFSC, 2009.

Disponível em: 
http://posgrad.fae.ufmg.br/posgrad/viienpec/pdfs/1033.pdf $>$. Acesso em: 17 jul. 2020.

PERUZZO, F. M.; CANTO, E. L. Química na abordagem do cotidiano. Vol. 1, 4a . Edição, Editora Moderna, São Paulo, 2006.

ROMANO, C. G.; CARVALHO, A. L.; MATTANO, I. D.; CHAVES, M. R. M.; ANTONIASSI, B.; Perfil Químico: Um Jogo para o Ensino da Tabela Periódica. Revista Virtual de Química, v. 9, n.3, p.1235-1244, 2017.

SANTANNA, I. M. Didática: aprender a ensinar. São Paulo: Loyola, 2015.

SEIXAS, R. H. M.; CALABRÓ, L.; SOUSA, D. O. A Formação de professores e os desafios de ensinar Ciências. THEMA, v. 14, n. 1, p. $289-303,2017$.

SILVA, A. C. R.; LACERDA, P. L.; CLEOPHAS, M. G. Jogar e compreender a Química: ressignificando um jogo tradicional em didático. Revista de Educação em Ciências e Matemática, v.13, n.28, Jul-Dez, p.132-150, 2017.

SILVA, J. B.; SALES, G. L.; CASTRO, J. B. Gamificação como estratégia de aprendizagem ativa no ensino de Física. Revista Brasileira de Ensino de Física, v. 41, n. 4, p.1-9, 2019.

SOARES, M. H. F. B. Jogos e Atividades Lúdicas no Ensino de Química: Teoria, Métodos e Aplicações. In: XIV ENCONTRO NACIONAL DE ENSINO DE QUÍMICA. Anais[...] Curitiba: UFPR, $2008 . \quad$ Disponível em: $<$ http://www.quimica.ufpr.br/eduquim/eneq2008/resumos/ Ro309-1.pdf>. Acesso em: 15 maio de 2020. 
SOARES, M. H. F. B.; REZENDE, F. A. de M. Análise Teórica e Epistemológica de Jogos para o Ensino de Química Publicado em Periódicos Científicos. Revista Brasileira De Pesquisa Em Educação Em Ciências, v.19, p.747-774, 2019.

SOARES, M. Jogos para o Ensino de Química: teoria, métodos e aplicações. Guarapari: Ex Libris, 2008.

TEIXEIRA, M. L.; KRÜGUE, A. G.; AIREZ, J. A. História e Filosofia da Ciência: Uma Proposta Didática para o Ensino da Tabela Periódica. XIX Encontro de Química da Região Sul, Tubarão, p.7-9, nov., 2012.

USBERCO, J.; SALVADOR, E. Química Geral. $12^{\mathrm{a}}$. ed. São Paulo: Saraiva, 2006.

VYGOTSKY, L. S. Pensamento e Linguagem. São Paulo: Martins Fontes, 2013.

WALON, H. Sociologia e educação. In: Psicologia e educação na infância. Lisboa: Stampa, p. 225-240, 2014.

ZANON, D. A. V.; GUERREIRO, M. A. S.; OLIVEIRA, R. C. Jogo didático Ludo Químico para o ensino de nomenclatura dos compostos orgânicos: projeto, produção, aplicação e avaliação. Ciências \& Cognição, v. 13, p. 72-81, 2008.

ZUB, L. O lúdico como motivador da aprendizagem em química para alunos da $1^{a}$ série do ensino médio do Colégio Estadual João XXIII em Irati - Paraná. Dissertação (Mestrado em Ensino de Ciência e Tecnologia) - Programa de PósGraduação em Ensino de Ciência e Tecnologia. Universidade Tecnológica Federal do Paraná. Ponta Grossa, 2012. 